Nano-subgrain Strengthening in Ball-milled Iron

D. R. Lesuer, C. K. Syn, O. D. Sherby

March 28, 2006

Materials Science and Engineering A 
This document was prepared as an account of work sponsored by an agency of the United States Government. Neither the United States Government nor the University of California nor any of their employees, makes any warranty, express or implied, or assumes any legal liability or responsibility for the accuracy, completeness, or usefulness of any information, apparatus, product, or process disclosed, or represents that its use would not infringe privately owned rights. Reference herein to any specific commercial product, process, or service by trade name, trademark, manufacturer, or otherwise, does not necessarily constitute or imply its endorsement, recommendation, or favoring by the United States Government or the University of California. The views and opinions of authors expressed herein do not necessarily state or reflect those of the United States Government or the University of California, and shall not be used for advertising or product endorsement purposes. 


\title{
Nano-subgrain strengthening in ball-milled iron
}

\author{
D.R. Lesuer ${ }^{{ }^{*}}$, C.K. Syn ${ }^{\mathrm{a}}$ and O.D. Sherby ${ }^{\mathrm{b}}$ \\ ${ }^{a}$ Lawrence Livermore National Laboratory, Livermore, CA 94551, USA \\ ${ }^{\mathrm{b}}$ Stanford University, Stanford, CA 94305 USA
}

\begin{abstract}
The strength and deformation behavior of ball-milled, iron-base materials containing nano-scale subgrains have been evaluated. As reported by several authors, nanosubgrains form during the early stages of ball milling as a result of severe plastic deformation inherent in the ball milling process. The strength for these nano-scale subgrains are compared with the strength of larger-scale subgrains in iron and iron-base alloys produced by traditional mechanical working. The data covers over 2 orders of magnitude in subgrain size (from $30 \mathrm{~nm}$ to $6 \mu \mathrm{m}$ ) and shows a continuous pattern of behavior. For all materials studied, the strength varied as $\lambda^{-1}$, where $\lambda$ is the subgrain size. Strengthening from subgrains was found to breakdown at a much smaller subgrain size than strengthening from grains. In addition, the ball-milled materials showed significant strengthening contributions from nano-scale oxide particles. Shear bands are developed during testing of ball-milled materials containing ultra-fine subgrains. A model for shear band development in nano-scale subgrains during deformation has also been developed. The model predicts a strain state of uniaxial compression in the shear band with a strain of -1.24. Subgrains are shown to offer the opportunity for high strength and good work hardening with the absence of yield point behavior.
\end{abstract}

Keywords: strength, subgrains, iron, ball milling

* Corresponding author: Tel: 925-422-9633; Fax: 925-422-2438

E-mail address: lesuer1@1lnl.gov

\section{Introduction}

Previous work on subgrain strengthening (see for example [1]) has shown that subgrains can provide significant contributions to the ambient temperature strength of iron and iron alloys. Most of these investigations have studied ferrous materials in which the subgraincontaining microstructures were produced by warm working (deformation at $0.4-0.6$ $\mathrm{T}_{\mathrm{m}}$, where $\mathrm{T}_{\mathrm{m}}$ is the absolute melting temperature). Mukherjee, Bird and Dorn [2] and Sherby and Burke [3] showed that the subgrain size developed during steady-state deformation varies in an inverse manner with the modulus normalized flow stress and is independent of solid solution alloying, crystal structure and stacking fault energy. This correlation provides important guidance on the choice of temperature and strain rate for warm working. Recently substantially finer subgrains have been obtained in iron powders processed by ball milling [4-12]. The subgrains form during the early stages of 
ball milling and result from the severe plastic deformation inherent in the ball milling process. The resulting subgrains can be less than $100 \mathrm{~nm}$ in size, which is finer than the subgrains produced by warm working.

In this paper we evaluate the strength and deformation behavior of ball-milled iron containing nano-subgrains. The results are compared with the strength and deformation behavior resulting from larger-scale subgrains in iron and iron-base alloys produced by traditional mechanical working. Strengthening from grain boundaries is also explored for iron and iron-containing alloys as a way of comparing grain boundary strengthening with subgrain boundary strengthening. The results of these analyses provide insight into subgrain strengthening mechanisms over a wide range of subgrain sizes.

\section{Subgrain strengthening}

\subsection{Grain strengthening and Hall-Petch behavior}

The strengthening contributions from grain boundaries in relatively simple iron-based materials and the applicability of the Hall-Petch relation have been analyzed. The materials for this analysis include several very pure irons [13,14] and an aged mild steel [15]. The yield strength $\left(\sigma_{\mathrm{y}}\right)$ - grain size $(\mathrm{L})$ data for these materials was analyzed according to the relation

$$
\sigma_{\mathrm{y}}=\sigma_{\mathrm{o}}+\mathrm{k}_{\mathrm{y}} \mathrm{L}^{-\mathrm{n}}
$$

where $\sigma_{\mathrm{o}}$ and $\mathrm{k}_{\mathrm{y}}$ are material constants and $\mathrm{n}$ is the grain size exponent. Rearranging Eqn 1 enables the strengthening contribution from grain boundaries $\left(\sigma_{\mathrm{gb}}\right)$ to be established as follows

$$
\sigma_{\mathrm{gb}}=\sigma_{\mathrm{y}}-\sigma_{\mathrm{o}}=\mathrm{k}_{\mathrm{y}} \mathrm{L}^{-\mathrm{n}}
$$

The $\sigma_{\mathrm{o}}$ chosen for the iron-based materials studied here was $28 \mathrm{MPa}$ [16], which is appropriate for interstitial-free iron. Plotting the resulting values of $\sigma_{\mathrm{gb}}$ as a function of grain size on log-log axes allows an unambiguous determination of the grain size exponent $n$ and doesn't pre-suppose Hall-Petch behavior in which $n$ would equal -1/2.

The results for the very pure irons and aged mild steel are shown in Fig. 1. The Armstrong et al data [13] was obtained on Swedish interstitial-free iron and the variation in grain size was obtained using different annealing treatments. The Tsuji et al data on interstial-free iron [14] shows significantly finer grain sizes that were produced by a severe plastic deformation (SPD) process involving repetitive rolling and stacking of sheet material. The data on interstial-free iron from the Armstrong et el and Tsuji et al studies provides grain sizes over almost two orders of magnitude and, as shown in Fig. 1, the stress-grain size data has a grain size exponent of $-1 / 2$ and thus shows excellent agreement with the Hall-Petch relation. Also shown in Fig. 1 is the classic work of Hall [15] in which strength-grain size studies were made on an aged mild steel $(\mathrm{Fe}-0.06 \% \mathrm{C})$. The data, which covers a grain size range of 7 to $50 \mu \mathrm{m}$, is parallel to the pure iron data 
and thus shows a grain size dependence of minus one-half. However the two data sets differ in strength by a factor of three. This difference in strength is no doubt related to the strengthening effects from the iron carbide particles that are present in the aged mild steel but absent from the pure iron. As shown by Lesuer, Syn and Sherby [17], the strength of such particle-hardened materials is proportional to the interparticle spacing to the minus one-half power.

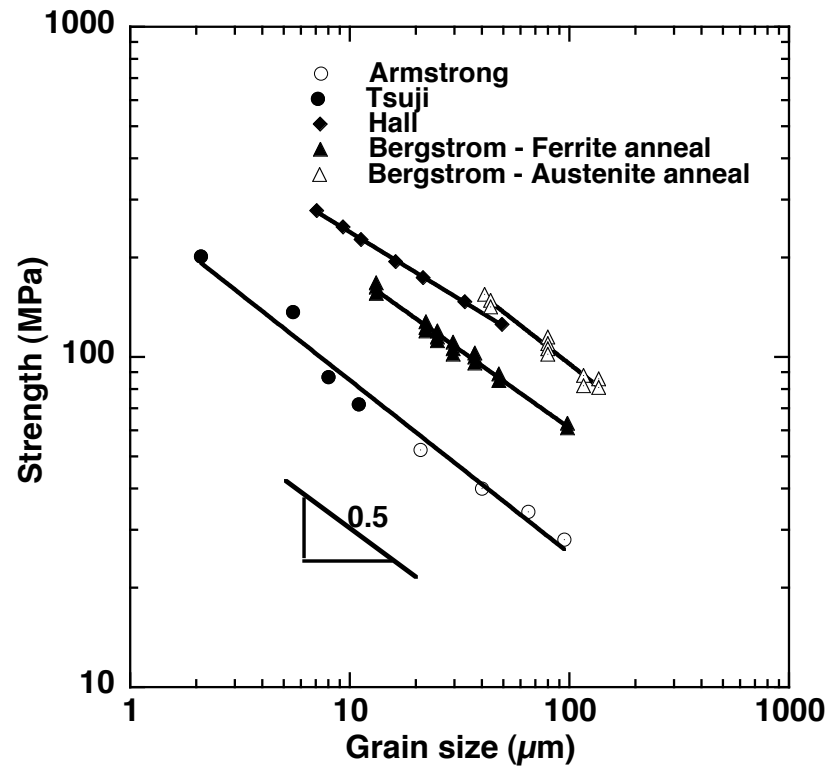

Fig. 1. Strength from grain boundaries versus grain size for iron and an aged mild steel containing coarse particles. Also shown in the figure is strengthgrain size data for a high purity "Orkla" iron after heat treatment in the ferrite and austenite regions.

Previous work by Lesuer, Syn and Sherby [17] on low carbon steels $(0.1$ to $0.3 \% \mathrm{C})$ has shown that the Hall-Petch relationship breaks down for grain sizes less than $8 \mu \mathrm{m}$. This breakdown was attributed to the loss in effectiveness of grain boundaries as barriers to slip due to increasing grain boundary relaxation with decreasing grain size. Grain boundary relaxation is a direct result of processes that are uniquely associated with high angle grain boundaries (and not subgrain boundaries) such as grain boundary sliding.

Figure 1 also shows the data of Bergstrom and Hallen [18] on high purity iron (called "Orkla" iron) that was obtained on two different sets of samples; one set was annealed in the ferrite region before testing and the other was annealed in the austenite region. The Bergstrom and Hallen study showed comparable values of $\sigma_{o}$ for the two data sets $(\sim 25$ $\mathrm{MPa})$. In addition, the results in Fig. 1 show that both materials show an $\mathrm{L}^{-0.5}$ dependence on grain size. However, the austenite-annealed material is significantly stronger than the ferrite-annealed material. One possible explanation for this behavior is that the austenite treatment may have caused impurities to go into solution and these impurities may have precipitated as fine particles at the grain boundaries upon cooling and transformation to the ferrite phase. It is reasonable to expect that these pinned boundaries provide greater resistance to slip and thus higher yield strengths, as observed in Fig. 1. The greater resistance to slip manifests itself as a greater value of $\mathrm{k}_{\mathrm{y}}$ in Eqn 1. 


\subsection{Subgrain development during ball milling}

Most yield strength studies for ball-milled, Fe-base materials report data for ball-milling times of 100 hours or greater. When much shorter ball milling times are used, for example 10 hours, the structure consists of subgrain boundaries rather than high angle boundaries. The evolution of subgrain formation during ball-milling is complex. This is because of the many variables involved that influence the structures developed including initial oxide content, ball-milling time, contamination of the powders, and subsequent steps of consolidating the powders. The later step involves heating, compacting, and further mechanical processing. Recent studies on ball-milled iron have shown that ultrafine subgrains form in the early stages of ball-milling (sometimes designated as dislocation cells or crystallites). These subgrains are on the order of 60 to $90 \mathrm{~nm}$ [4]. When these powders are compacted and warm worked to obtain consolidated material, the subgrains coarsen to about $1 \mu \mathrm{m}$, but remarkably remain as low angle boundaries [5]. The data of Yin et al [6] would suggest that subgrains might still dominate the structure up to about 50 hours of ball milling.

Table 1 summarizes the important characteristics of the ball-milled iron materials studied here. The table provides the powder composition, general processing history, resulting subgrain size and the basis for the strength data. All these iron-base materials were ballmilled for 20 hours or less [Jia et al (20 hours), Jang and Koch (0.17-0.5 hours), Sakai et al (10 hours), Belyakov et al (20 hours), and Kimura et al (4-6 hours)] and have microstructures containing a large fraction of subgrain boundaries. The Belyakov et al and the Sakai et al studies were conducted on powders containing large (and intentional) volume fractions of oxide.

Table 1

Investigations of Ball-Milled Iron Containing Sub-grains

\begin{tabular}{|l|l|l|l|l|}
\hline \multicolumn{1}{|c|}{$\begin{array}{c}\text { Investigators, } \\
\text { year [reference] }\end{array}$} & $\begin{array}{c}\text { Powder } \\
\text { composition } \\
\text { before milling }\end{array}$ & $\begin{array}{c}\text { Milling } \\
\text { time }(\mathrm{h})\end{array}$ & $\begin{array}{c}\text { Subgrain size } \\
\text { range }(\mu \mathrm{m})\end{array}$ & \multicolumn{1}{|c|}{ Processing and testing } \\
\hline $\begin{array}{l}\text { J.S. Jang and } \\
\text { C.C. Koch, 1990 } \\
\text { [7] }\end{array}$ & $\begin{array}{l}99.5 \% \mathrm{Fe}, \\
0.9 \mathrm{at} \% \mathrm{O}, \\
26 \mathrm{ppm} \mathrm{N}\end{array}$ & $0.17-0.5$ & $.060-.029$ & $\begin{array}{l}\text { Hardness measured on milled } \\
\text { powder particles. }\end{array}$ \\
\hline $\begin{array}{l}\text { Kimura, Hidaka } \\
\text { and Takaki, 1999 } \\
\text { [8] }\end{array}$ & $\begin{array}{l}99.2 \% \mathrm{Fe} \\
\text { (Industrial pure } \\
\mathrm{Fe} \text { ) }\end{array}$ & $4-6$ & $.065-.19$ & $\begin{array}{l}\text { Hardness measured on milled } \\
\text { powders and material } \\
\text { compacted at } 4 \text { GPa and } \\
\text { sintered at } 550^{\circ} \mathrm{C} \text { for } .5 \mathrm{~h} .\end{array}$ \\
\hline $\begin{array}{l}\text { Y. Sakai et al., } \\
\text { 2000 [9] }\end{array}$ & $\begin{array}{l}\mathrm{Fe}-0.43 \% \mathrm{O} \text { and } \\
\mathrm{Fe}-0.18 \% \mathrm{O}\end{array}$ & 10 & $1-2$ & $\begin{array}{l}\text { Tensile test data obtained on } \\
\text { milled powder degassed } \\
480 \mathrm{C} / 15 \mathrm{~h} \text {, consolidated via } \\
\text { rolling } 86 \% \text { at } 700^{\circ} \mathrm{C}\end{array}$ \\
\hline $\begin{array}{l}\text { A. Belyakov et } \\
\text { al., 2004 [10] }\end{array}$ & $\mathrm{Fe}-0.6 \% \mathrm{O}$ & 20 & $1.2-1.65$ & $\begin{array}{l}\text { Tensile test and hardness data } \\
\text { on material consolidate via } \\
\text { rolling } 86 \% \text { at } 700^{\circ} \mathrm{C}\end{array}$ \\
\hline $\begin{array}{l}\text { D. Jia et al., 2003 } \\
\text { [11] }\end{array}$ & $99.9 \% \mathrm{Fe}$ & 18 (typical) & $.08-.98$ & $\begin{array}{l}\text { Uniaxial compression tests on } \\
\text { consolidated material; cold } \\
\text { pressed then hot pressed at } 480 \\
-680^{\circ} \mathrm{C}\end{array}$ \\
\hline
\end{tabular}




\subsection{Subgrain strengthening in ball-milled materials.}

Early ball-milling studies of iron by Jang and Koch [7] and by Kimura and Takaki [18] indicate that subgrain boundaries might be significant contributors to the strength of powders when ball-milled for short times. The influence of subgrain boundaries on strength is shown in Fig. 2 for the five studies summarized in Table 1. In some of these studies hardness data was reported whereas in other studies yield strength data was directly determined. For the cases in which hardness data is reported, the hardness numbers were converted to yield strength by $\mathrm{H}_{\mathrm{v}}=3 \sigma_{\mathrm{y}}$ for hardness values below $\mathrm{H}_{\mathrm{v}}=6.5$ [19] and $H_{v}=2.5 \sigma_{y}$ for hardness numbers above 6.5 [19]. Because of the short ball milling times, subgrains will be prevalent and the strength is reported as a function of subgrain size. The data was analyzed by a power-law, strength-subgrain size relation analogous to Eqn. 1. The value of $\sigma_{o}$ in this relation was assumed to be zero for these studies except for the work of Kimura et al on the $99.2 \%$ pure powders. For this material, the authors estimated that $\sigma_{\mathrm{o}}$ was equal to $13 \mathrm{MPa}$ [8].

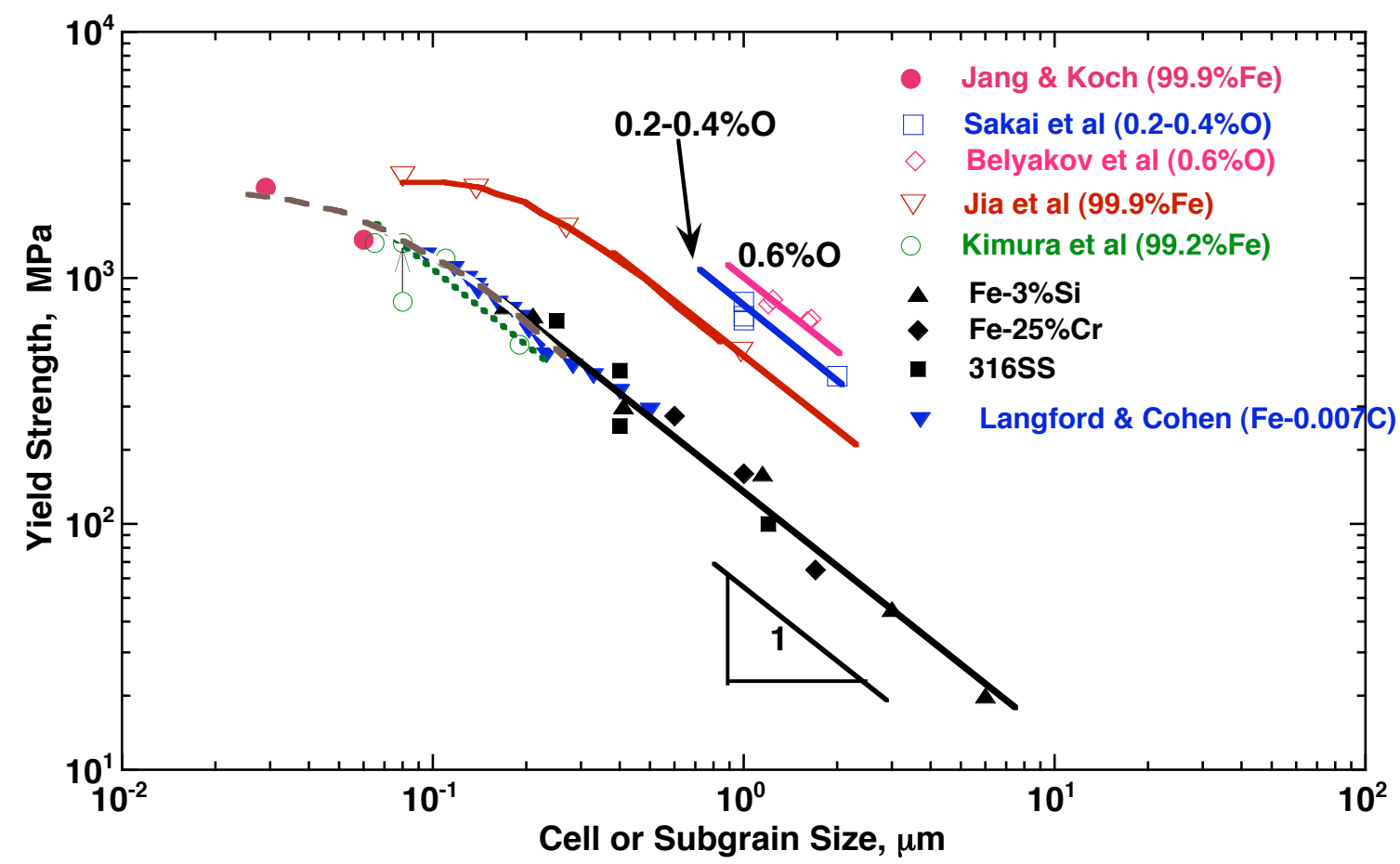

Fig. 2. Yield strength versus subgrain size for ball-milled irons and several wrought iron materials. These wrought iron materials include three solid solutions of iron that were mechanically worked in torsion and a Fe-.007C material that was wire drawn.

In addition to the ball-milled data, Fig. 2 also shows strength-subgrain size data for iron and iron-base alloys that have been processed by traditional procedures of casting followed by mechanical working to achieve different subgrain sizes. In most cases, such studies are free from unexpected contamination (such as observed in some powder processed materials) and from adiabatic shear banding. These processed materials provide a base line to compare with the ball-milling studies of iron shown in Fig. 2 . Included in the figure are data for three solid solution alloys of iron $(\mathrm{Fe}-3 \% \mathrm{Si}, \mathrm{Fe}-25 \% \mathrm{Cr}$ and 316 stainless steel) from Young and Sherby [1] and for essentially pure iron (Fe- 
0.007C) from Langford and Cohen [20]. The solid solution alloys were processed by warm torsion deformation and the pure iron was processed by wire drawing to various strains at room temperature. The strengths of the iron and solid solution iron alloys were shown by Langford and Cohen [20] and Young and Sherby [1] to vary in a reciprocal manner with subgrain size according to the following relation.

$$
\sigma_{\mathrm{y}}=\mathrm{B} \lambda^{-1}+\sigma_{\mathrm{o}}
$$

where $\sigma_{\mathrm{y}}$ is the yield strength, $\lambda$ is the subgrain size, $\mathrm{B}$ is a constant and $\sigma_{0}$ is the matrix strength. The constant $\mathrm{B}$, which is a measure of the subgrain boundary as a barrier to slip, has been shown to be a function of the misorientation angle in the subgrain boundary and impurity interactions with dislocations in the subgrain boundary. Figure 2 compares the results from wrought iron alloys with the results from ball-milled iron. The data are plotted as $\sigma_{\lambda}=\sigma_{\mathrm{y}}-\sigma_{\mathrm{o}}$ where $\sigma_{\mathrm{o}}$ is $200 \mathrm{MPa}$ for the solid solution alloys and $34 \mathrm{MPa}$ for the pure iron. The wrought iron data illustrate the slope of -1 expected for subgrain boundary strengthening following traditional warm working process. In addition, the Kimura et al data for $99.2 \% \mathrm{Fe}$ and the Jang and Koch data for $99.5 \% \mathrm{Fe}$ fall in line with the wrought data. The ball milled powder and wrought data cover over two orders of magnitude in subgrain size $(30 \mathrm{~nm}$ to $6 \mu \mathrm{m})$ and show a continuous pattern of behavior. Over most of the subgrain size range $(0.1 \mu \mathrm{m}$ to $6 \mu \mathrm{m})$, a subgrain size exponent of -1 is observed.

\subsection{Breakdown in $\lambda^{-1}$ behavior}

The Kimura et al study [8] and the Jang and Koch study [7] provide data at the smallest subgrain sizes, which was determined from hardness measurements on the nonconsolidated ball-milled powders. These data correlate quite well with the wrought steel studies but suggest a breakdown of the $\lambda^{-1}$ relation beginning at about $0.10 \mu \mathrm{m}$. For traditional grain boundary strengthening, a breakdown in the strength-grain size relation at small grain sizes is often associated with grain boundary sliding. For subgrain boundary strengthening, the breakdown in the relation cannot be related to subgrain boundary sliding since such boundaries only migrate and do not slide. However, shear band instabilities in the subgrain boundaries may exist at ultra-fine sizes. The mechanical property studies of ball-milled iron by Jia et al provide evidence for this instability. Their data are given in Fig. 2 and the $\lambda^{-1}$ relation is followed for the data points at larger subgrain sizes but appears to breakdown at subgrain sizes below about $0.20 \mu \mathrm{m}$. Their studies on ball-milled iron (99.9\% pure) were conducted on consolidated material obtained by cold and hot pressing in the temperature range of 480 to $680^{\circ} \mathrm{C}$. The authors noted shear bands in their compression tests of the $0.138 \mu \mathrm{m}$ grain size material where the strain was measured to be two orders of magnitude larger in the shear band than outside the shear band. The subgrains in the shear band became highly elongated indicating their instability. It should be noted that the data of Jia et al in Fig. 2 show a higher strength than the data taken on processed powders particles data (data of Kimura et al and Jang and Koch)). This difference is likely a result of the use of ultra-fine powders of iron by Jia et al, $5 \mu \mathrm{m}$, in contrast to about $75 \mu \mathrm{m}$ in the other studies. These ultra-fine powders will have large amounts of an ultra-fine oxide layer that will be broken up by the ball-milling process. These ultrafine oxide particles will strengthen the 
material. The parallel displacement of the strength differential may have its origin in the same way that was observed for the strength differential from grain size strengthening (Fig. 1). That is, the subgrain/grain size and the particle size change cooperatively during strain-time-temperature processing.

One important distinction between subgrain boundary strengthening and grain boundary strengthening is the size scale at which strengthening begins to break down. As noted in Section 2.1, for the iron alloys studied by Lesuer, Syn and Sherby [17], Hall Petch behavior broke down for grain sizes less than $8 \mu \mathrm{m}$. For subgrain strengthening, however, deviations from $\lambda^{-1}$ behavior were observed at a much smaller size scale, i.e. subgrain sizes less than $.1-.2 \mu \mathrm{m}$. The greater stability of subgrain size strengthening with decreasing size scale is a direct result of the greater resistance exhibited by subgrain boundaries to boundary relaxation processes that reduce the effectiveness of the boundary as a barrier to dislocation motion.

\subsection{Influence of oxide particles}

The Sakai et al data (15) and Belyakov et al data (16) in Fig. 2 were derived from powders that were deliberately oxidized prior to ball-milling (with contents of $0.2,0.4$ and $0.6 \mathrm{wt} \%$ oxygen). A major purpose of these studies was to obtain consolidated material that would exhibit higher strain hardening characteristics from oxide particles and result in higher tensile ductility properties. The short ball-milling times (10-20 hours) and the subsequent consolidation steps limited the subgrain size range of study to the micron size range. The data shown in Fig. 2 support the $\lambda^{-1}$ relation expected for subgrain boundary strengthening. The three points that are connected by a slope of minus one for the 0.2 and $0.4 \mathrm{wt} \% \mathrm{O}$ powders involve the following processing history. The higher strength points, at one micron subgrain size, are for the two different composition iron oxide powders, processed by ball-milling for 10 hours and then consolidated by warm rolling to e $=2.0$ at $700^{\circ} \mathrm{C}$. The yield strengths are approximately the same with the $0.2 \% \mathrm{O}$ material showing slightly higher strength than the $0.4 \% \mathrm{O}$ material. The points are connected to a point at two microns for the same two powders that were not ballmilled by were consolidated by the same warm rolling procedure. It is concluded that the strength of short-time ball-milled iron is a complex interrelated function of the sub-grain size and of oxide particle size, distribution and volume fraction. It would appear that short ball milling times could prove to be an important processing method for obtaining attractive properties. Sakai et al have shown that the consolidated sample of $0.4 \% \mathrm{O}$ mentioned above has a tensile strength of $735 \mathrm{MPa}$, a uniform elongation of $7 \%$ and a total elongation of $15 \%$.

\section{Deformation behavior involving nano-scale subgrains}

\subsection{Shear band development during deformation of subgrains}

The work of Jia et al [11] is particularly interesting because the authors showed shear bands to form under compression deformation at room temperature. These bands formed on materials that were processed to obtain subgrain sizes of $80,138 \mathrm{~nm}$ and $268 \mathrm{~nm}$. It is significant to point out that these materials showed very high yield strengths, 2800, 2500 
and $1700 \mathrm{MPa}$ respectively. The bands were shown to form in the direction of the shear plane, and the width of the band was found to be a function of the subgrain size. The shear band width was $6.8 \mu \mathrm{m}$ for the $138 \mathrm{~nm}$ material and $16.4 \mu \mathrm{m}$ for the $268 \mathrm{~nm}$ material. The ratio of the band width to the subgrain size was shown to be a constant equal to about 55 (Table 2 in the Jia et al paper). TEM studies were centered on the structure within the shear band for the $138 \mathrm{~nm}$ subgrain size material. Figure 3 is a reproduction of Fig. 9 in the Jia et al paper [11] showing (a) the structure within the shear band (b) outside the shear band. An unusual observation was made by the authors in that the photomicrograph "shows elongated grains (elongated along the shear direction) containing high dislocation densities". No evidence of recrystallization was observed within the bands, and the shear band boundaries were noted to be relatively sharp. Further, no gradient of microstructure is observed across the shear bands. A possible explanation will be presented with respect to the unusual change in the structure of the subgrains during shear banding.

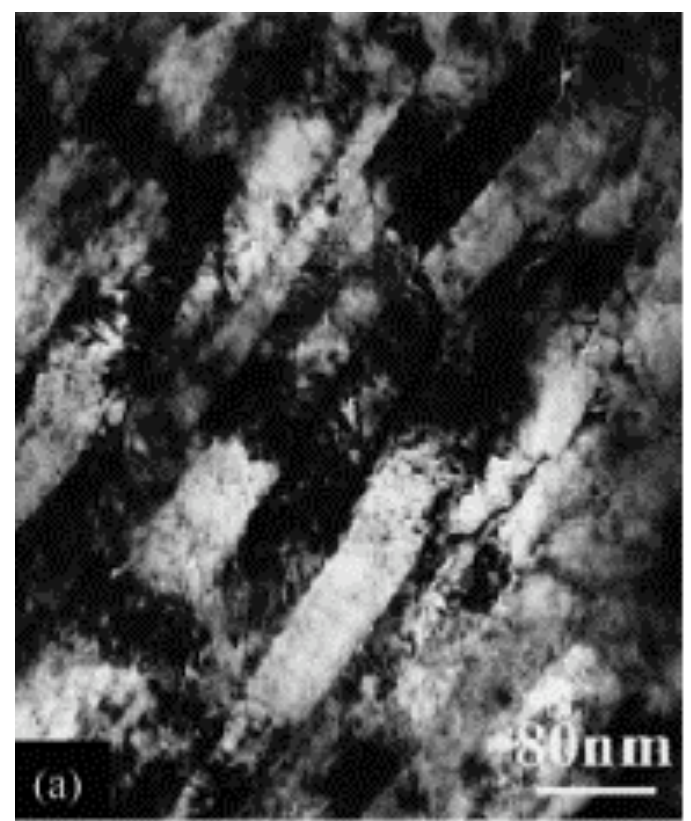

(a)

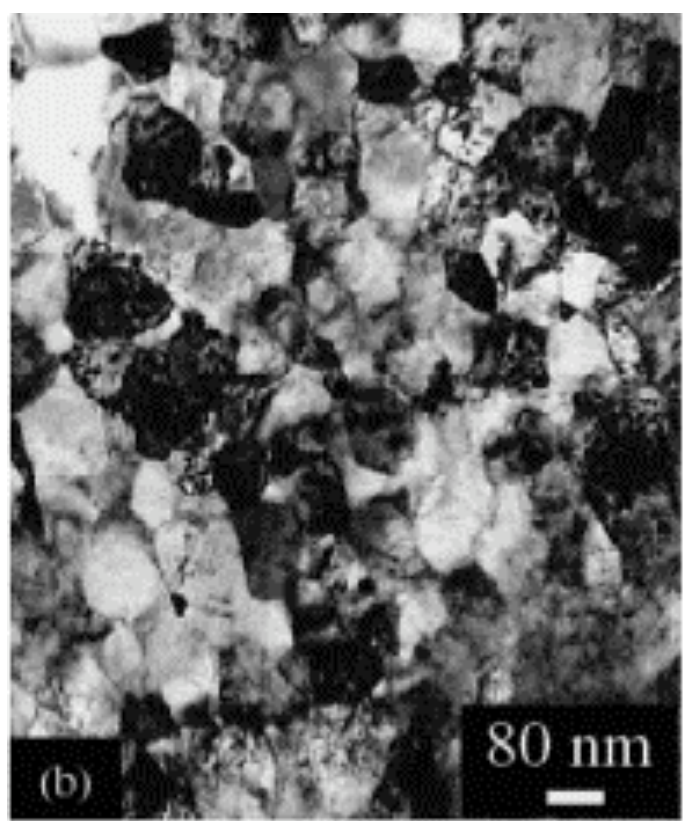

(b)

Fig. 3. TEM micrographs of a region containing a shear band for the deformed 138 $\mathrm{nm}$ Fe sample, a) inside the shear band and b) outside the shear band, from the work of Jia et al (11). The micrographs show different magnifications as indicated by the scale marker.

It is proposed that the stress state at the propagating band influences the mechanism of deformation occurring within the band. Furthermore, it is proposed that the presence of subgrains and not grains results in some of the microstructural changes observed by the authors. A schematic depiction of the shear bands developed during compression deformation is shown in Fig. 4a based on the photomicrographs of Jia et al on the $288 \mathrm{~nm}$ subgrain size material. In the early stages of compression deformation, a number of shear bands form, approximately $16 \mu \mathrm{m}$ wide. After continued compression deformation, new thinner bands develop perpendicular to the primary ones. The secondary band reveals a small shear displacement after intersecting the major band, as schematically shown in 
Fig. 4a. A shear strain of about 0.2 was deduced by the present authors from their photographs that are in agreement with the estimate of 0.25 quoted by Jia et al estimated by another method. It will be shown that, in addition to this shear strain, there is a large compression strain contribution to the total deformation within the shear band. This arises from the resolved compression stress on the shear band, $\sigma_{\mathfrak{c}^{\prime}}$, calculated from the Tresca relation, $\sigma_{\mathrm{c}}{ }^{\prime}=\sigma_{\mathrm{c}} / 2$, where $\sigma_{\mathrm{c}}$ is the uniaxial stress. The compressive stress on the band is shown in Fig. 4a. The equivalent shear stress, $\tau$, equal to $\sigma_{\mathrm{c}} / 2$ is also shown in the figure.

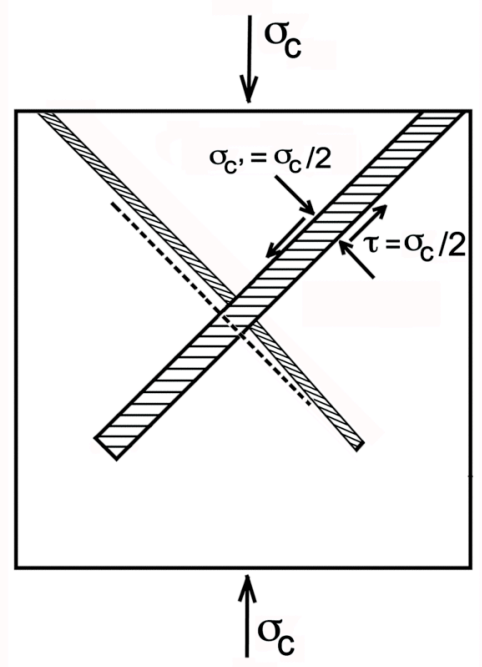

(a)

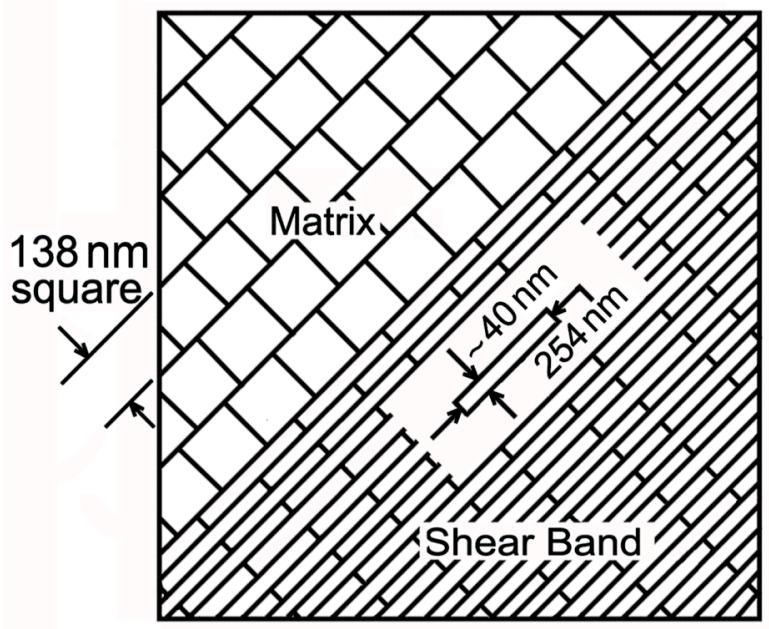

(b)

Fig. 4. Schematic drawings for the proposed model of deformation within a shear band, a) intersecting primary and secondary shear bands and b) microstructure at the boundary of the shear band and the matrix.

It is possible to make an estimate of the compression strain from the TEM photomicrographs given by Jia et al shown in Fig. 3. These micrographs are for the material processed to achieve an average subgrain size of $138 \mathrm{~nm}$. As noted in Fig. 3a, the microstructure within the shear band shows elongated subgrains that are parallel to the shear propagation direction, i.e. perpendicular to compression stress, $\sigma_{\mathrm{c}}$. The average thickness of these subgrains is $40 \mathrm{~nm}$ instead of the initial subgrain size of $138 \mathrm{~nm}$. It is therefore, appropriate to conclude that the subgrains were compression deformed and widened, rather than elongated (a strain state of uniaxial compression). The true strain, $\varepsilon$, in compression is given by $\ln 1_{1} / l_{0}$ where $l_{1}$ is the thickness of the subgrain in the shear band $(40 \mathrm{~nm})$, and $1_{0}$ is the original subgrain dimension $(138 \mathrm{~nm})$ yielding $\varepsilon=-1.24$. On the assumption of constancy of volume per subgrain, and with isotropic deformation, the width of the subgrain is predicted to be $254 \mathrm{~nm}$. These dimensions are illustrated in Figure $4 \mathrm{~b}$ where the dissimilar structures in the shear band and the adjoining matrix are shown. For simplification, the subgrains are depicted as squares and rectangles. The predicted subgrain aspect ratio $(254 / 40=6.2)$ is observed in some instances in the Jia et al photomicrograph that confirms our prediction. There are other regions where the grain aspect ratio is smaller than 6 , but always much greater than 1 . The smaller aspect ratio can be expected since additional dislocations are created during shear banding that can form new subgrain boundaries within the widened subgrains. 
The proposed model gives another view on the process of deformation during shear banding. It is that, at least in some cases, deformation within the band is by sideways deformation from the uniaxial stress, but its propagation direction is controlled by the maximum shear stress direction. The proposed mechanism could be applicable to the case for high angle boundary grains. The complication from grain boundary sliding in this case as an added deformation mechanism, however, may yield a different structure. There is the probability that the shear bands observed by Jia et al are the well known adiabatic shear bands. This possibility arises from the expected increase in temperature from the large strain, e.g. $\varepsilon=-1.24$ and the high accompanying strengths $(2500,2300$ and 1500 $\mathrm{MPa}$, for the 80, 138 and $268 \mathrm{~nm}$ material respectively). We estimate a rise in temperature of above $500^{\circ} \mathrm{C}$ is readily achieved in the highest strength material. On the other hand, when the strength was $520 \mathrm{MPa}$ for a subgrain size of $980 \mathrm{~nm}$, no shear bands were observed by Jia et al. This is expected since the temperature rise from deformation would be quite small.

\subsection{Work hardening and yield point phenomena}

There are many factors that may favor the practical application of Fe-based materials containing subgrains. Perhaps one of the most compelling reasons, relative to metal forming, is the influence of subgrains on yield point phenomena. Data from Young et al [21] compares the different influence of grains and subgrains on yield point phenomena in a mild steel $(\mathrm{Fe}-0.17 \mathrm{C})$. The data in Fig. 5a shows the stress-plastic strain response for the mild steel in a well-annealed condition, which produced high angle grain boundaries. The steel exhibits classic yield point behavior and subsequent inhomogenous plastic flow. The data in Fig. 5b, however, shows the stress-plastic strain response for steel samples that were warm rolled at three different temperatures. These three treatments produced material with fine subgrains. The material warm rolled at the highest temperature $\left(647^{\circ} \mathrm{C}\right)$ shows a tendency for yield point phenomena as indicated by the lack of hardening in the low strain region of the stress-strain curve. However warm rolling at lower temperatures generally produced finer subgrains, showed hardening after yield and no tendency for yield point behavior. These results for the material warm rolled at $537^{\circ} \mathrm{C}$ were particularly impressive, since the finest subgrain size was produced $(0.25 \mu \mathrm{m})$ which had a yield strength of $607 \mathrm{MPa}$. This yield strength is higher than the lower yield strength observed in the $0.42 \mu \mathrm{m}$ grain-size, annealed material, which showed pronounced yield point behavior. Thus subgrains appear to be a microstructural feature which can produce high strength and good work hardening with the absence of yield point behavior.

These benefits from subgrains may result from the structure of the subgrain boundary, which consists of ordered dislocation arrays and the affinity for interstitial atoms to segregate to these dislocation arrays. The extensive subgrain boundary networks in the warm worked material are expected to be sufficient to accommodate all the interstitials present in the mild steel. 


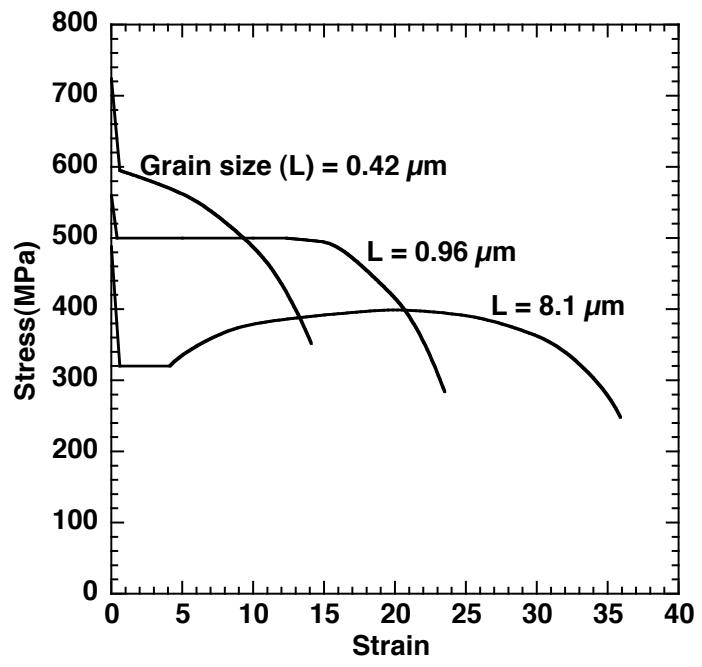

(a)

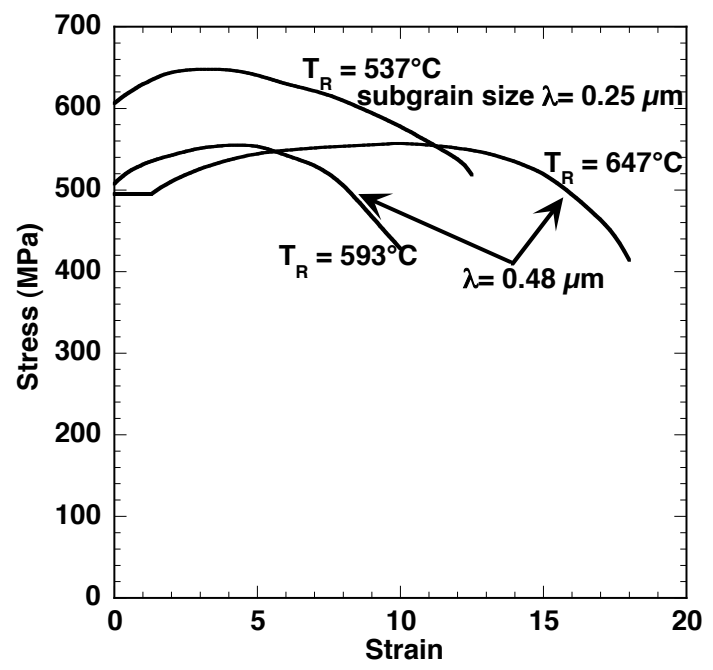

(b)

Fig. 5. Stress versus plastic strain for a mild steel (Fe-0.17C) showing the influence of grains (a) and subgrains (b) on yield point behavior and hardening response, after Young, Walser, Abrahamson and Sherby [21].

\section{Summary and Conclusions}

Iron powders, when ball milled for short times (less than 20 hours), develop nano-scale subgrains. These subgrains are retained after consolidation and warm working. The strength of these iron-base materials with nano-scale subgrains has been evaluated and compared with the strength of iron and iron alloys containing subgrains produced by traditional metal working. It is shown that the strengthening due to subgrains varies as $\lambda^{-1}$, where $\lambda$ is the subgrain size. This $\lambda^{-1}$ relation breaks down at a subgrain size of approximately $150 \mathrm{~nm}$. This behavior contrasts with strengthening due to grain boundaries in which break down for a low-C, iron alloy was observed at a grain size of 8 $\mu \mathrm{m}$. The ball-milled materials also showed significant strengthening contributions from nano-scale oxide particles. Shear bands are developed during testing of ball-milled materials containing ultra-fine subgrains. A model for shear band development in nanoscale subgrains during deformation has also been developed. The model predicts a strain state of uniaxial compression in the shear band with a strain of -1.24. Subgrains appear to offer the opportunity for high strength and good work hardening with the absence of yield point behavior. The absence of yield point behavior is attributed to the subgrain boundary network acting as a sink for interstitial atoms. Subgrain strengthening offers additional unique benefits including 1) strengthening from subgrains is not lost at fine subgrain sizes because grain boundary sliding does not take place and 2) at fine subgrain sizes, significant strain hardening is observed.

\section{References}

[1] C.M. Young and O.D. Sherby, J Iron and Steel Inst., 211 (1973) 640.

[2] A.K. Mukherjee, J.E. Bird and J.E. Dorn, Trans. ASM 62 (1969) 155.

[3] O.D. Sherby and P.M. Burke, Prog. Mater. Sci. 13 (1968) 325. 
[4] H. Hidaka, K. Kawasaki, T. Tsuchiyama and S. Takaki, Mater. Trans. JIM 44 (2003) 1912.

[5] A. Belyakov, Y. Sakai, T. Hara, Y. Kimura and K. Tsuzaki: Metall. Mater. Trans. 33A (2002) 3241.

[6] J. Yin, M. Umemoto, Z.G. Liu and K. Tsuchiya, ISIJ Intern. 41 (2001) 1389.

[7] J. C. S Jang and C. C. Koch: Scripta Metall. Mater. 24 (1990) 1599.

[8] Y. Kimura, H. Hidaka and S. Takaki, Mater. Trans. JIM 40 (1999) 1149.

[9] Y. Sakai, M. Otaguchi, Y. Kimura and K. Tsuzaki, Ultrafine Grained Materials, ed. by R. S. Mishra et al, TMS, Warrendale, PA, 2000, p. 361.

[10] A. Belyakov, Y. Sakai, T. Hara, Y. Kimura and K. Tsuzaki, Mater. Trans. JIM 45 (2004) 2252.

[11] D. Jia, K.T. Ramesh and E. Ma, Acta Mater. 51 (2003) 3495.

[12] Y. Kimura and S. Takaki, Mater. Trans. JIM 36, 2 (1995) 289.

[13] R. Armstrong, L. Codd, R. M. Douthwaite and N. J. Petch: Phil. Mag. 7 (1962) 45.

[14] N. Tsuji, S. Okuno, Y. Koizumi and Y. Minamino: Mater. Trans. JIM 45 (2004) 2272.

[15] E.O. Hall, Proc. Roy. Soc. B54 (1951) 747.

[16] A. Cracknell and N. J. Petch: Acta Metall. 3 (1955) 186.

[17] D.R. Lesuer, C.K. Syn and O.D. Sherby, submitted to Matls Trans (2006).

[18] Y. Bergstrom and H. Hallen, Metal Science, 17 (1983) 341.

[19] A. Belyakov, Y. Sakai, T. Hara, Y. Kimura and K. Tsuzaki, Metall. Mater. Trans. 32A (2001) 1769.

[20] G. Langford and M. Cohen, Trans ASM, ASM, 62 (1969) 623.

[21] C.M. Yound, B. Walser, E. P. Abrahamson and O.D. Sherby, Scripta Metall. 9 (1975) 35.

\section{Acknowledgements}

This work was performed under the auspices of the U. S. Department of Energy by the University of California, Lawrence Livermore National Laboratory under Contract No. W-7405-Eng-48. 